\title{
UTILIZAÇÃO DE ZEÓLITAS SINTETIZADAS A PARTIR DE XISTO RETORTADO NA REMOÇÃO DE ARSÊNIO EM ÁGUAS CONTAMINADAS
}

\author{
Nádia Regina Camargo Fernandes-Machado* e Denise Maria Malachini Miotto-Bigatão \\ Departamento de Engenharia Química, Universidade Estadual de Maringá, Av. Colombo, 900, 87020-900 Maringá - PR, Brasil
}

Recebido em 17/5/06; aceito em 28/11/06; publicado na web em 2/7/07

\begin{abstract}
USE OF ZEOLITES SYNTHESIZED FROM OIL SHALE ASH FOR ARSENIC REMOVAL FROM POLLUTED WATER. The solid by-product of the oil shale processing (PETROBRAS - Brazil) was used as raw material to synthesize zeolites A and faujasite. Alkaline fusion followed by hydrothermal treatment was the synthesis procedure used, and five different starting material compositions were obtained. The more crystalline zeolite-type materials synthesized, the pretreated oil shale ash and commercial zeolites were used as adsorbents in the purification of pollutant solutions with arsenic. The zeolite-type material composed of a mixture of zeolite A (42.6\%) and faujasite (52.9\%) presented an ion exchange capacity comparable to the pure zeolites A and faujasite, much better than the pretreated ash.
\end{abstract}

Keywords: zeolites; oil shale ash; arsenic.

\section{INTRODUÇÃO}

O Brasil possui a segunda reserva mundial de xisto oleígeno e desenvolveu uma tecnologia própria para extração do óleo do xisto da formação Irati, denominado Processo Petrosix ${ }^{1}$. Atualmente, no complexo industrial de beneficiamento de xisto da Unidade de Negócio da Industrialização do Xisto - SIX (PETROBRAS) em São Mateus do Sul - PR, 6600 t/dia de xisto cru são pirolisados a $500{ }^{\circ} \mathrm{C}$ em atmosfera inerte, produzindo óleo e gás e gerando 6000 t/dia de xisto retortado como subproduto $(90 \%$ em massa do xisto cru processado). Esse resíduo sólido representa prejuízo à economia do Processo Petrosix.

Grande parte dos esforços em pesquisa e desenvolvimento realizados com xistos oleígenos brasileiros está voltada para o estudo de sua fração orgânica, principalmente sua utilização como combustível. Por outro lado, pouco se tem estudado sobre a natureza dos seus constituintes inorgânicos, que representam de 80 a $90 \%$ em massa do material ${ }^{2}$. A composição mineralógica e a estrutura lamelar do xisto retortado são semelhantes às de argilas, que são comumente usadas como matéria-prima em síntese de zeólitas ${ }^{3}$. Este fato motivou a presente investigação de síntese de zeólitas a partir de xisto retortado.

A síntese hidrotérmica de zeólitas, através de transformações de materiais zeolíticos e outros silicatos naturais, tem sido utilizada devido à busca de fontes baratas de $\mathrm{Al}$ e $\mathrm{Si}$, visando a obtenção de rotas alternativas de produção de adsorventes e trocadores iônicos, com grande aplicação em processos de purificação e separação $0^{4,5}$.

A recuperação de metais pesados em soluções diluídas por meio dos métodos clássicos é ineficiente ${ }^{6}$. Desta forma, considerando a política ambiental atual, a utilização de zeólitas como adsorventes de baixo custo consiste em uma forma alternativa aos métodos de precipitação química e coagulação para a remoção de metais pesados de águas e efluentes industriais ${ }^{7}$. Além do baixo custo, a utilização de zeólitas na remoção de metais apresenta outras vantagens, tais como a regeneração da zeólita com $\mathrm{NaCl}$, a seletividade

\footnotetext{
*e-mail: nadia@deq.uem.br
}

de forma, tamanho e carga conferida pela estrutura zeolítica e, a estabilidade térmica e resistência à radiação ${ }^{8}$.

$\mathrm{O}$ arsênio é um elemento altamente tóxico, presente principalmente em águas de abastecimento e alimentos marinhos, e sua contaminação pode causar dermatites, câncer de pele, efeitos neurológicos, doenças do coração e cânceres internos. Diversas técnicas estão sendo desenvolvidas para remover o arsênio da água e, nesse contexto, o processo de adsorção aparece como um método promissor ${ }^{9,10}$.

O objetivo deste estudo consistiu, primeiramente, em sintetizar zeólitas A e faujasita a partir de xisto retortado pré-tratado, agregando valor ao subproduto gerado no Processo Petrosix e, posteriormente, avaliar a eficiência dos materiais zeolíticos sintetizados na purificação de águas contaminadas com arsênio.

\section{PARTE EXPERIMENTAL}

Todas as soluções foram preparadas com água desionizada Milli-Q (18 M $\Omega \mathrm{cm}$ ) e reagentes de grau analítico: $\mathrm{HCl}$ (Merck); $\mathrm{Al}_{2} \mathrm{O}_{3}$ (Catapal B, Sasol); $\mathrm{NaOH}$ (Laborclin); solução padrão de As $1000 \mathrm{mg} / \mathrm{L}$ (SpecSol).

\section{Pré-tratamento do xisto retortado}

O xisto retortado foi fornecido pela PETROBRAS-SIX na forma sólida, com coloração negra, devido à presença de carbono depositado, e com resíduos de pneus, devido ao co-processamento de pneus usados e xisto cru na Retorta do Processo Petrosix. O pré-tratamento do xisto retortado consistiu nos tratamentos mecânico, térmico e ácido. Inicialmente, foram retirados manualmente do material sólido os arames oriundos dos pneus, sendo então triturado e peneirado, selecionando-se as partículas menores que 0,044 mm. Em seguida, o xisto retortado (amostras com cerca de $20 \mathrm{~g}$ ) foi submetido à calcinação gradativa até $800{ }^{\circ} \mathrm{C}$, em atmosfera oxidante, permanecendo nessa temperatura por $4 \mathrm{~h}$, para garantir a máxima volatilização do material orgânico presente. Finalmente, o xisto retortado calcinado foi submetido ao tratamento ácido. A lixiviação ácida consistiu na mistura de $10 \mathrm{~g}$ de xisto retortado calcinado a $40 \mathrm{~mL}$ de solução de $\mathrm{HCl}(5 \mathrm{~mol} / \mathrm{L})$ em balão de fundo redondo com condensador de refluxo acoplado, durante $4 \mathrm{~h}$, a $100^{\circ} \mathrm{C}$. Após o término do tratamento 
ácido, a suspensão foi filtrada, lavada com água desionizada e seca em estufa a $100{ }^{\circ} \mathrm{C}$ por $24 \mathrm{~h}$.

\section{Caracterização da matéria-prima}

A composição química do xisto retortado antes e após os tratamentos térmico e ácido foi determinada por fluorescência de raios X (Philips MagiX PRO). A morfologia do xisto retortado calcinado e lixiviado foi observada por microscopia eletrônica de varredura (Microscópio Leica Steroscan 440).

\section{Procedimento de síntese de zeólitas}

O procedimento de síntese adotado foi a fusão alcalina seguida de tratamento hidrotérmico, baseado no trabalho de Chang e Shih ${ }^{11}$. $\mathrm{Na}$ fusão alcalina, a mistura sólida (xisto retortado calcinado e lixiviado $+\mathrm{Al}_{2} \mathrm{O}_{3}($ Catapal $\mathrm{B}, \mathrm{Sasol})+\mathrm{NaOH}$ (Laborclin)) foi calcinada a $350^{\circ} \mathrm{C}$ por $2 \mathrm{~h}$ em reator de teflon. Após resfriamento da massa alcalina fundida, foi adicionada água desionizada e a mistura foi agitada por $3 \mathrm{~h}$ em temperatura ambiente. $\mathrm{O}$ gel formado foi envelhecido por $24 \mathrm{~h}$, sem agitação, a temperatura ambiente, e em seguida foi cristalizado em estufa a $100{ }^{\circ} \mathrm{C}$, sem agitação, por $6,12,24,48,72$ e $96 \mathrm{~h}$. O produto obtido foi filtrado, lavado com água desionizada e seco em estufa a $100{ }^{\circ} \mathrm{C}$ por $24 \mathrm{~h}$.

Foram testadas cinco composições da mistura reagente:

[1] $3 \mathrm{SiO}_{2} \cdot \mathrm{Al}_{2} \mathrm{O}_{3} \cdot 4,2 \mathrm{Na}_{2} \mathrm{O} \cdot 256,2 \mathrm{H}_{2} \mathrm{O}$

[2] $3 \mathrm{SiO}_{2} \cdot \mathrm{Al}_{2} \mathrm{O}_{3} \cdot 5,7 \mathrm{Na}_{2} \mathrm{O} \cdot 228 \mathrm{H}_{2} \mathrm{O}$

[3] $3 \mathrm{SiO}_{2} \cdot \mathrm{Al}_{2} \mathrm{O}_{3} \cdot 10,5 \mathrm{Na}_{2} \mathrm{O} \cdot 325,5 \mathrm{H}_{2} \mathrm{O}$

[4] $3 \mathrm{SiO}_{2} \cdot \mathrm{Al}_{2} \mathrm{O}_{3} \cdot 4,2 \mathrm{Na}_{2} \mathrm{O} \cdot 130,2 \mathrm{H}_{2} \mathrm{O}$

[5] $3 \mathrm{SiO}_{2} \cdot \mathrm{Al}_{2} \mathrm{O}_{3} \cdot 5,7 \mathrm{Na}_{2} \mathrm{O} \cdot 176,7 \mathrm{H}_{2} \mathrm{O}$

que tiveram variações nos teores de $\mathrm{NaOH}$ e água adicionados ao sistema, com objetivo de avaliar o efeito dos dois componentes.

\section{Caracterização dos produtos de síntese}

Os produtos de síntese foram identificados por difração de raios-X em difratômetro Rigaku Miniflex (radiação $\mathrm{Cu}-\mathrm{K} \alpha$ filtrada com Ni). A composição química dos materiais zeolíticos foi determinada por fluorescência de raios X (Philips MagiX PRO) e a razão Si/Al estrutural foi calculada por ressonância magnética nuclear de ${ }^{29} \mathrm{Si} \mathrm{com} \mathrm{rotação} \mathrm{do} \mathrm{ângulo} \mathrm{mágico} \mathrm{em} \mathrm{espectrômetro}$ Varian Mercury Plus BB $300 \mathrm{MHz}$. A morfologia dos cristais foi observada por meio de microscopia eletrônica de varredura em Microscópio Leica Steroscan 440, com detector de elétrons secundários.

\section{Teste de troca iônica com arsênio}

Os testes de remoção de arsênio por troca iônica foram realizados com o xisto retortado pré-tratado, com as zeólitas comerciais A e a faujasita tipo-X, e com os materiais zeolíticos mais cristalinos. Todos os experimentos utilizaram processos descontínuos sob agitação, baseados no estudo de Shevade e Ford ${ }^{9}$. Uma alíquota de $20 \mathrm{~mL}$ de solução de arsênio $70 \mathrm{mg} / \mathrm{L}$ foi adicionada a um erlenmeyer com $100 \mathrm{mg}$ de adsorvente. $\mathrm{O}$ pH da suspensão foi ajustado em 7,5 e a temperatura do sistema foi mantida a $30{ }^{\circ} \mathrm{C}$ em banho termostático. As bateladas tiveram duração de 30 min. Em seguida, os materiais com melhor desempenho foram submetidos a uma sequiência de bateladas (10, 20, 30 min, 1, 2, 3, 6 e 24 h) para obtenção da curva cinética de troca iônica com arsênio. Ao final de cada experimento, a suspensão foi centrifugada e a solução límpida foi analisada por espectrofotometria de absorção atômica.

\section{RESULTADOS E DISCUSSÃO}

\section{Pré-tratamento do xisto retortado}

A composição química do xisto retortado antes e após os tratamentos térmico e ácido está descrita na Tabela 1 .

O tratamento térmico removeu $83,6 \%$ do resíduo carbonoso presente no xisto após retortagem, resultando em um material com baixo teor $(2,3 \%)$ de matéria orgânica remanescente. No tratamento ácido, foi verificada uma elevada solubilização de $\mathrm{Fe}_{2} \mathrm{O}_{3}(91 \%)$, apesar de também ter ocorrido uma redução indesejável de $\mathrm{Al}_{2} \mathrm{O}_{3}$ $(24,7 \%)$. O ferro, por competir com o alumínio na estrutura tetraédrica das zeólitas, necessita ser eliminado. Dessa forma, o pré-tratamento do xisto retortado foi considerado eficiente.

A Figura 1 mostra as micrografias do xisto retortado calcinado e lixiviado.

$\mathrm{O}$ ataque ácido destruiu a estrutura lamelar original do xisto retortado, gerando vacâncias e rugosidades na sua superfície. Uma grande distribuição de tamanho de partículas também foi observada, sendo que as partículas maiores foram formadas provavelmente na etapa de calcinação, devido às sinterizações ocorridas nos microporos e parte dos mesoporosos.

\section{Difração de raios $\mathrm{X}$ dos produtos de síntese}

As Figuras 2 a 6 apresentam os difratogramas de raios $\mathrm{X}$ dos produtos de síntese obtidos a partir das composições [1] a [5], respectivamente, e as cristalinidades relativas das amostras estão mostradas nas Tabelas 2 a 6.

Tabela 1. Composição química do xisto retortado antes e após o pré-tratamento

\begin{tabular}{|c|c|c|c|c|c|}
\hline $\begin{array}{l}\text { Constituintes } \\
(\% \mathrm{~m} / \mathrm{m})\end{array}$ & $\begin{array}{l}\text { Xisto retortado } \\
\text { cru }(\%)\end{array}$ & $\begin{array}{l}\text { Xisto retortado } \\
\text { calcinado }(\%)\end{array}$ & $\begin{array}{c}\text { Xisto retortado } \\
\text { calcinado e lixiviado }(\%)\end{array}$ & $\begin{array}{c}\text { Redução na } \\
\text { calcinação }(\%)\end{array}$ & $\begin{array}{c}\text { Redução na } \\
\text { lixiviação ácida (\%) }\end{array}$ \\
\hline $\mathrm{SiO}_{2}$ & 56,1 & 64,1 & 79,7 & $* * * *$ & $* * * *$ \\
\hline $\mathrm{Al}_{2} \mathrm{O}_{3}$ & 13,9 & 14,6 & 11,0 & $* * * *$ & 24,7 \\
\hline $\mathrm{Fe}_{2} \mathrm{O}_{3}$ & 6,4 & 9,2 & 0,83 & $* * * *$ & 91,0 \\
\hline $\mathrm{CaO}^{3}$ & 2,6 & 2,4 & 0,62 & 7,7 & 74,2 \\
\hline $\mathrm{MgO}$ & 2,1 & 2,2 & 0,95 & $* * * *$ & 56,8 \\
\hline $\mathrm{Na}_{2} \mathrm{O}$ & 1,6 & 1,8 & 1,7 & $* * * *$ & 5,6 \\
\hline $\mathrm{K}_{2} \mathrm{O}$ & 2,9 & 2,9 & 2,2 & $* * * *$ & 24,1 \\
\hline $\mathrm{TiO}_{2}$ & 0,4 & 0,5 & 0,7 & $* * * *$ & $* * * *$ \\
\hline Perda ao fogo & 14,0 & 2,3 & 2,3 & 83,6 & $* * * *$ \\
\hline
\end{tabular}

****Não houve redução 


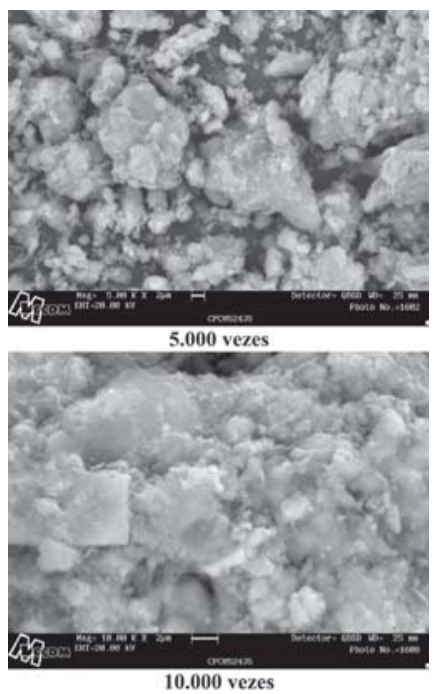

Figura 1. Micrografias do xisto retortado calcinado e lixiviado com duas ampliações

As fases cristalinas desejadas foram as zeólitas A e faujasita, mas em muitos casos foram obtidas fases mais estáveis, tais como as zeólitas hidroxissodalita e NaP1. As zeólitas A e faujasita produzidas foram quantificadas utilizando-se zeólitas padrão A e faujasita tipo-X, e sua cristalinidade relativa foi determinada por meio da Equação 1. As zeólitas $\mathrm{NaP1}$ e hidroxissodalita, por sua vez, não foram quantificadas devido à falta de padrões para análise de difração de raios $X$.

$\%$ Cristalinidade $=\left(\frac{\sum \text { Intensidade dos picos de DRX do produto }}{\sum \text { Intensidade dos picos de DRX do padrão }}\right) \times 100(1)$

É importante ressaltar que os difratogramas apresentados a seguir não estão na mesma escala, de modo que a análise apenas por comparação da intensidade de seus picos não é correta.

A composição dos materiais zeolíticos sintetizados a partir da composição [1] (Figura 2, Tabela 2) variou principalmente em fun-

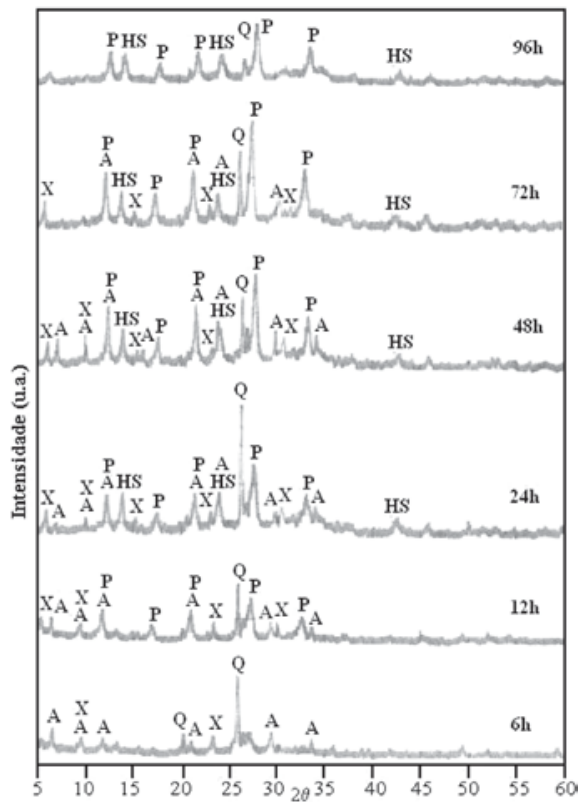

Figura 2. DRX dos produtos obtidos a partir da composição [1]. A: zeólita A; X: zeólita faujasita; $\boldsymbol{P}$ : zeólita NaP1; HS: zeólita hidroxissodalita; $\boldsymbol{Q}$ : quartzo
Tabela 2. Produtos a partir da composição [1]

\begin{tabular}{|c|c|}
\hline $\begin{array}{l}\text { Tempo de } \\
\text { cristalização (h) }\end{array}$ & Fases zeolíticas obtidas \\
\hline 6 & 27,1\% zeólita A; 9,7\% faujasita \\
\hline 12 & $\begin{array}{c}30,5 \% \text { zeólita } \mathrm{A} ; 15,1 \% \text { faujasita; } \\
\text { zeólita } \mathrm{NaP} 1\end{array}$ \\
\hline 24 & $\begin{array}{l}23,1 \% \text { zeólita A; } 19,1 \% \text { faujasita; } \\
\text { zeólitas } \mathrm{NaP1} \text { e HS }\end{array}$ \\
\hline 48 & $\begin{array}{l}34,0 \% \text { zeólita A; } 20,6 \% \text { faujasita; } \\
\text { zeólitas NaP1 e HS }\end{array}$ \\
\hline 72 & $\begin{array}{c}\text { 8,8\% zeólita A; } 25,9 \% \text { faujasita; } \\
\text { zeólitas NaP1 e HS }\end{array}$ \\
\hline 96 & zeólitas $\mathrm{NaP} 1$ e HS \\
\hline
\end{tabular}

ção do tempo submetido ao tratamento hidrotérmico. A zeólita A foi formada inicialmente com $6 \mathrm{~h}$ de tratamento hidrotérmico e alcançou sua máxima cristalinidade $(34,0 \%)$ após 48 h de cristalização. Quanto à zeólita faujasita, seu teor foi aumentado com o aumento do tempo de cristalização, alcançando sua máxima cristalinidade $(25,9 \%)$ em $72 \mathrm{~h}$ de tratamento hidrotérmico. A baixa reatividade da composição [1] resultou na formação limitada das estruturas zeolíticas desejadas. Em períodos de síntese mais longos, as fases metaestáveis LTA e FAU foram redissolvidas e recristalizadas nas estruturas mais estáveis hidroxissodalita e NaP1.

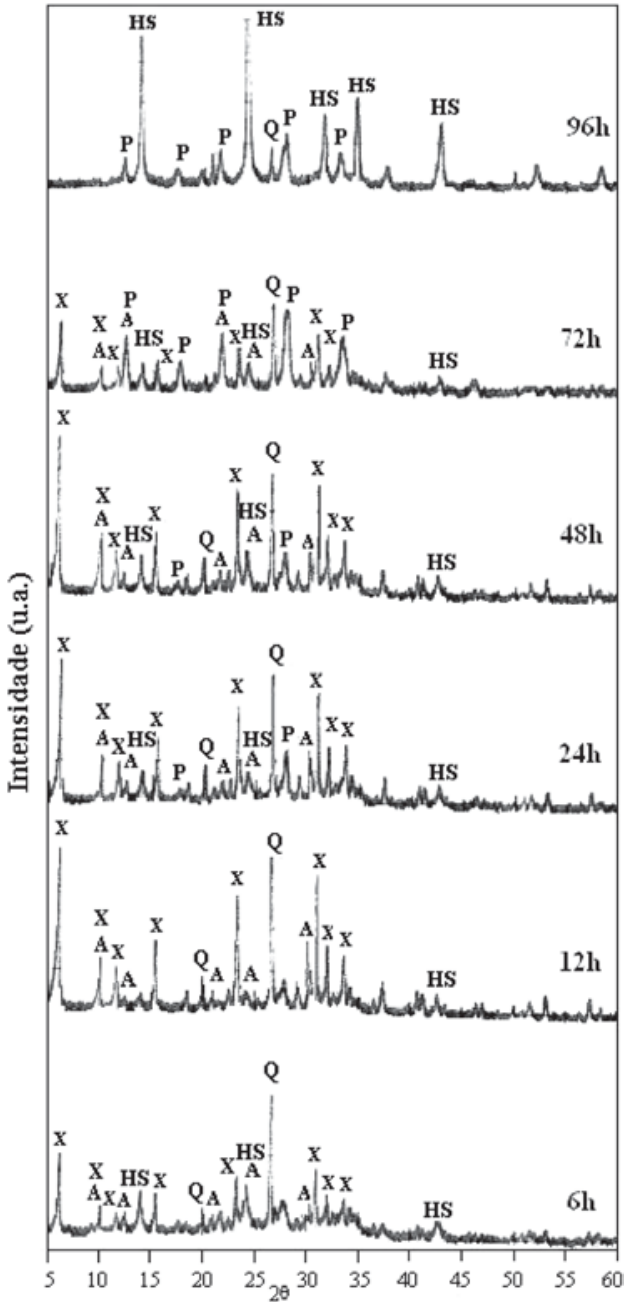

Figura 3. DRX dos produtos obtidos a partir da composição [2]. A: zeólita A; X: zeólita faujasita; $\boldsymbol{P}$ : zeólita NaP1; HS: zeólita hidroxissodalita; $\boldsymbol{Q}$ : quartzo 
Tabela 3. Produtos a partir da composição [2]

\begin{tabular}{|c|c|}
\hline $\begin{array}{l}\text { Tempo de } \\
\text { cristalização (h) }\end{array}$ & Fases zeolíticas obtidas \\
\hline 6 & $\begin{array}{c}\text { 18,5\% zeólita A; } 48,0 \% \text { faujasita; } \\
\text { zeólita HS }\end{array}$ \\
\hline 12 & $\begin{array}{c}\text { 20,9\% zeólita A; } 71,9 \% \text { faujasita; } \\
\text { zeólita HS }\end{array}$ \\
\hline 24 & $\begin{array}{l}\text { 17,8\% zeólita A; } 65,0 \% \text { faujasita; } \\
\text { zeólitas NaP1 e HS }\end{array}$ \\
\hline 48 & $\begin{array}{c}17,7 \% \text { zeólita } \mathrm{A} ; 66,1 \% \text { faujasita; } \\
\text { zeólitas } \mathrm{NaP1} \text { e HS }\end{array}$ \\
\hline 72 & $\begin{array}{l}\text { 13,5\% zeólita A; } 40,6 \% \text { faujasita; } \\
\text { zeólitas NaP1 e HS }\end{array}$ \\
\hline 96 & zeólitas NaP1 e HS \\
\hline
\end{tabular}

A composição da mistura reagente [2] (Figura 3, Tabela 3) favoreceu a síntese da zeólita faujasita, formando após $12 \mathrm{~h}$ de tratamento hidrotérmico um produto zeolítico com $71,9 \%$ de faujasita, e mantendo um elevado teor da estrutura FAU até $48 \mathrm{~h}$ de cristalização. A síntese da zeólita A, por outro lado, foi limitada pela concentração da mistura reagente, e sua cristalinidade foi mantida praticamente constante até $48 \mathrm{~h}$ sob tratamento hidrotérmico. Após 96 $\mathrm{h}$ de cristalização, foram obtidas as zeólitas $\mathrm{NaP} 1$, em menor proporção, e hidroxissodalita, com elevada cristalinidade.

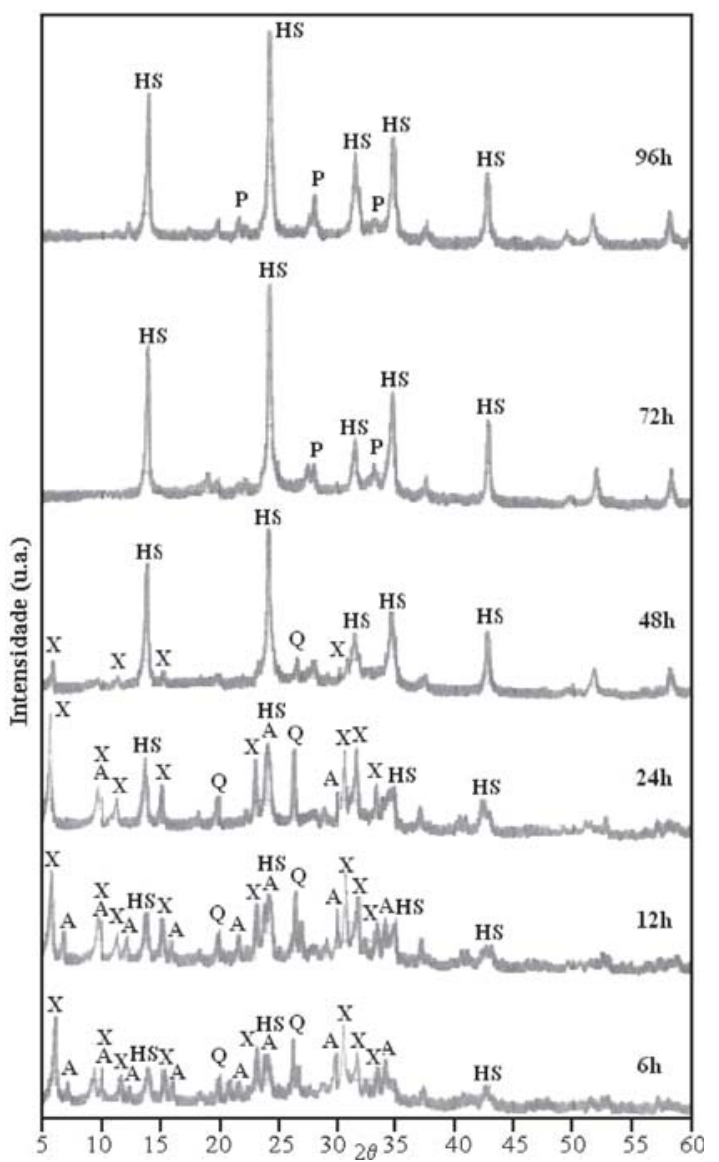

Figura 4. DRX dos produtos obtidos a partir da composição [3]. A: zeólita A; X: zeólita faujasita; P: zeólita NaP1; HS: zeólita hidroxissodalita; $\mathbf{Q}$ : quartzo

A elevada reatividade da composição [3] (Figura 4, Tabela 4) levou à formação de materiais zeolíticos com alta cristalinidade em tempos curtos de cristalização. Após $12 \mathrm{~h}$ de tratamento
Tabela 4. Produtos a partir da composição [3]

\begin{tabular}{lc}
\hline $\begin{array}{l}\text { Tempo de } \\
\text { cristalização }(\mathrm{h})\end{array}$ & Fases zeolíticas obtidas \\
\hline 6 & $40,0 \%$ zeólita A; $49,2 \%$ faujasita; \\
zeólita HS \\
12 & $42,6 \%$ zeólita A; $52,9 \%$ faujasita; \\
zeólita HS \\
24 & 13,2\% zeólita A; $52,4 \%$ faujasita; \\
& zeólita HS \\
48 & $21,0 \%$ faujasita; \\
& zeólita HS \\
72 & zeólitas NaP1 e HS \\
96 & zeólitas NaP1 e HS \\
\hline
\end{tabular}

hidrotérmico, obteve-se o produto com a maior cristalinidade em zeólita A $(42,6 \%)$ e faujasita $(52,9 \%)$. Após 48 h de cristalização, foi verificada a transformação dessas fases metaestáveis principalmente em hidroxissodalita, além da completa dissolução do quartzo, ambas devido à alcalinidade acentuada do meio reacional. Outros estudos com resultados semelhantes concluíram que a elevada alcalinidade gerou uma supersaturação de espécies Si e Al dissolvidas e favoreceu a nucleação de fases metaestáveis, como a faujasita, que em seguida se redissolveram e recristalizaram, e foram substituídas por fases mais estáveis, como a hidroxissodalita ${ }^{12}$.

A composição [4] foi obtida reduzindo-se a quantidade de água adicionada à composição [1], encontrando-se uma relação molar $\mathrm{Na}_{2} \mathrm{O} / \mathrm{H}_{2} \mathrm{O}$ igual à da composição [3]. A mesma relação foi verificada entre as composições [5] e [2].

Na Figura 5, a formação da zeólita A, assim como ocorreu com a composição [1], foi limitada pela pequena quantidade de $\mathrm{NaOH}$ adicionado ao sistema, atingindo uma cristalinidade máxima de apenas 26,4\% em $12 \mathrm{~h}$ de tratamento hidrotérmico. Por outro lado, a zeólita faujasita foi formada com elevada cristalinidade, como observado com as composições [2] e [3]. As fases NaP1 e hidroxissodalita também foram identificadas nos produtos de síntese, nos quais se observou maior concentração de NaP1 somente após 96 h de cristalização, quando o quartzo começou a ser consumido pelo meio reacional.

Partindo da composição [5] (Figura 6, Tabela 6), novamente foi observada a formação preferencial da zeólita faujasita, atingindo uma elevada cristalinidade em curto período de tratamento hidrotérmico, enquanto a zeólita A foi discretamente formada. O aumento da concentração de $\mathrm{NaOH}$ em relação à composição [2] levou à formação da zeólita hidroxissodalita mais rapidamente, atingindo elevada cristalinidade após 72 h de cristalização. Já a zeólita NaP1 foi produzida em pequena quantidade, assim como observado com a composição [2].

$\mathrm{O}$ procedimento de fusão da mistura alcalina favoreceu, em todas as composições utilizadas, a formação da zeólita faujasita, como verificado anteriormente em outros trabalhos ${ }^{11-13}$. A limitação da síntese da zeólita A ocorreu em função da quantidade insuficiente de espécies de $\mathrm{Al}$ no meio reacional ${ }^{11}$. Como todos os experimentos deste trabalho partiram da mesma quantidade de $\mathrm{Al}_{2} \mathrm{O}_{3}$, a composição [3], com o maior teor de $\mathrm{NaOH}$, foi a mais efetiva na dissolução das espécies Al do xisto retortado pré-tratado, favorecendo a formação da zeólita A.

O material zeolítico produzido a partir da composição [3] após $12 \mathrm{~h}$ de cristalização (C3T12) apresentou a maior cristalinidade em zeólita A $(42,6 \%)$ e um baixo teor de quartzo. Por outro lado, o produto obtido a partir da composição [2] após $12 \mathrm{~h}$ de tratamento hidrotérmico (C2T12) apresentou a maior cristalinidade em zeólita 


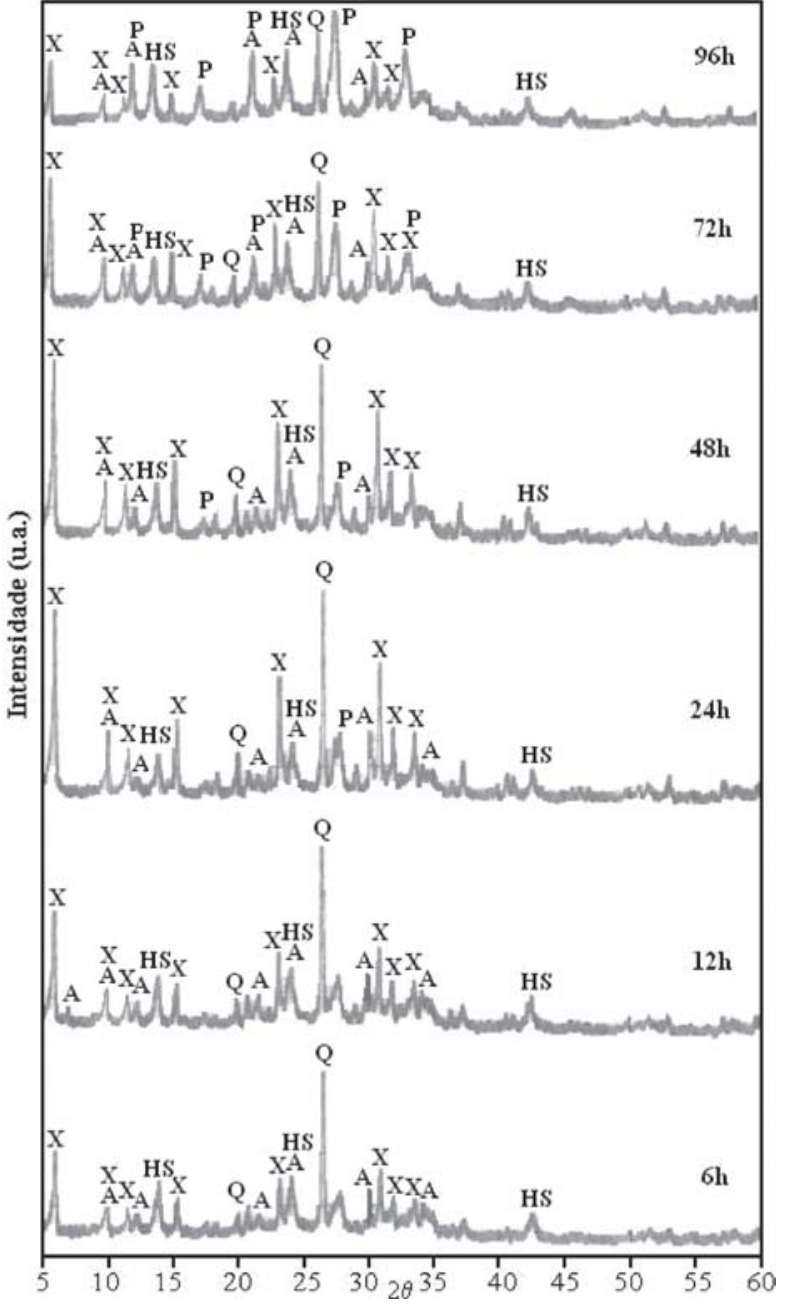

Figura 5. DRX dos produtos obtidos a partir da composição [4]. A: zeólita A; X: zeólita faujasita; P: zeólita NaP1; HS: zeólita hidroxissodalita; Q: quartzo

Tabela 5. Produtos a partir da composição [4]

\begin{tabular}{|c|c|}
\hline $\begin{array}{l}\text { Tempo de } \\
\text { cristalização (h) }\end{array}$ & Fases zeolíticas obtidas \\
\hline 6 & $\begin{array}{c}\text { 17,7\% zeólita A; } 43,5 \% \text { faujasita; } \\
\text { zeólita HS }\end{array}$ \\
\hline 12 & $\begin{array}{c}\text { 26,4\% zeólita A; } 49,8 \% \text { faujasita; } \\
\text { zeólita HS }\end{array}$ \\
\hline 24 & $\begin{array}{l}\text { 16,7\% zeólita A; } 66,1 \% \text { faujasita; } \\
\text { zeólitas NaP1 e HS }\end{array}$ \\
\hline 48 & $\begin{array}{l}12,7 \% \text { zeólita A; } 64,5 \% \text { faujasita; } \\
\text { zeólitas NaP1 e HS }\end{array}$ \\
\hline 72 & $\begin{array}{c}\text { 8,3\% zeólita A; } 52,2 \% \text { faujasita; } \\
\text { zeólitas NaP1 e HS }\end{array}$ \\
\hline 96 & $\begin{array}{c}8,0 \% \text { zeólita A; } 35,1 \% \text { faujasita; } \\
\text { zeólitas NaP1 e HS }\end{array}$ \\
\hline
\end{tabular}

faujasita $(71,9 \%)$. Por se destacarem dos demais produtos, esses dois materiais foram selecionados para serem caracterizados e testados na remoção de arsênio de águas contaminadas.

\section{Caracterização dos materiais zeolíticos}

A composição química dos materiais zeolíticos C3T12 e C2T12

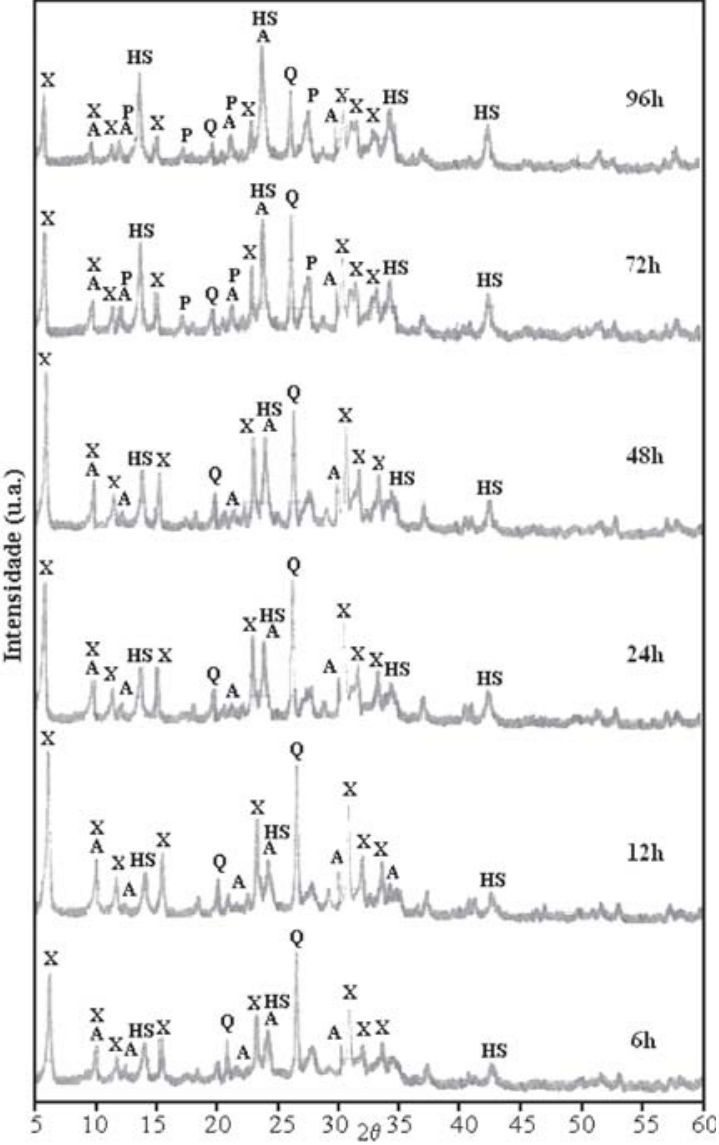

Figura 6. DRX dos produtos obtidos a partir da composição [5]. A: zeólita A; X: zeólita faujasita; P: zeólita NaP1; HS: zeólita hidroxissodalita; $Q$ : quartzo

Tabela 6. Produtos a partir da composição [5]

\begin{tabular}{lc}
\hline $\begin{array}{l}\text { Tempo de } \\
\text { cristalização }(\mathrm{h})\end{array}$ & Fases zeolíticas obtidas \\
\hline 6 & $10,1 \%$ zeólita A; $49,2 \%$ faujasita; \\
zeólita HS \\
12 & $\begin{array}{c}20,9 \% \text { zeólita A; } 61,6 \% \text { faujasita; } \\
\text { zeólita HS }\end{array}$ \\
24 & $\begin{array}{r}\text { zeólita A; } 58,0 \% \text { faujasita; } \\
\text { zeólita HS }\end{array}$ \\
48 & $\begin{array}{r}\text { zeólita A; } 60,0 \% \text { faujasita; } \\
\text { zeólita HS }\end{array}$ \\
72 & $\begin{array}{r}10,5 \% \text { zeólita A; } 48,8 \% \text { faujasita; } \\
\text { zeólitas NaP1 e HS }\end{array}$ \\
96 & $\begin{array}{c}\text { zeólita A; } 43,1 \% \text { faujasita; } \\
\text { zeólitas NaP1 e HS }\end{array}$ \\
\hline
\end{tabular}

foi determinada por fluorescência de raios X (Tabela 7) e, a partir dela, calculou-se a razão molar $\mathrm{Si} / \mathrm{Al}$ global desses produtos, enquanto suas razões molares $\mathrm{Si} / \mathrm{Al}$ estrutural foram determinadas a partir do seu espectro de ressonância magnética nuclear de ${ }^{29} \mathrm{Si}$. A Tabela 8 compara os dois parâmetros calculados.

Assim como a matéria-prima antes e após o pré-tratamento, os materiais zeolíticos C3T12 e C2T12 apresentaram impurezas, que não foram completamente eliminadas no procedimento de síntese, mas foram reduzidas, principalmente devido ao aumento do teor de $\mathrm{Na}_{2} \mathrm{O}$ e $\mathrm{Al}_{2} \mathrm{O}_{3}$, adicionados durante a síntese.

As razões molares $\mathrm{Si} / \mathrm{Al}$ global e estrutural foram muito seme- 
Tabela 7. Composição química dos materiais zeolíticos C2T12 e C3T12

\begin{tabular}{lcc}
\hline $\begin{array}{l}\text { Constituintes } \\
(\% \mathrm{~m} / \mathrm{m})\end{array}$ & $\begin{array}{c}\text { Material zeolítico } \\
\text { C2T12 }\end{array}$ & $\begin{array}{c}\text { Material zeolítico } \\
\mathrm{C} 3 \mathrm{~T} 12\end{array}$ \\
\hline $\mathrm{SiO}_{2}$ & 44,22 & 37,62 \\
$\mathrm{Al}_{2} \mathrm{O}_{3}$ & 28,77 & 29,43 \\
$\mathrm{Fe}_{2} \mathrm{O}_{3}$ & 0,47 & 0,39 \\
$\mathrm{CaO}$ & 0,45 & 0,32 \\
$\mathrm{MgO}$ & 0,36 & 0,32 \\
$\mathrm{Na}_{2} \mathrm{O}$ & 12,96 & 16,65 \\
$\mathrm{~K}_{2} \mathrm{O}$ & 0,59 & 0,24 \\
$\mathrm{TiO}_{2}$ & 0,56 & 0,46 \\
$\mathrm{Perda}$ & 11,62 & 14,57 \\
\hline
\end{tabular}

Tabela 8. Razões molares Si/Al global e estrutural dos produtos $\mathrm{C} 2 \mathrm{~T} 12$ e $\mathrm{C} 3 \mathrm{~T} 12$

\begin{tabular}{lcc}
\hline Materiais zeolíticos & $\begin{array}{r}\text { Razão molar } \\
\text { Si/Al global }\end{array}$ & $\begin{array}{c}\text { Razão molar } \\
\text { Si/Al estrutural }\end{array}$ \\
\hline Produto de síntese C2T12 & 1,31 & 1,26 \\
Produto de síntese C3T12 & 1,10 & 1,09 \\
\hline
\end{tabular}

lhantes, indicando que o silício presente nos produtos está inserido nas fases zeolíticas, fazendo parte da estrutura cristalina. O produto $\mathrm{C} 2 \mathrm{~T} 12$, rico em faujasita, apresentou maior razão $\mathrm{Si} / \mathrm{Al}$ em função do menor número de átomos de $\mathrm{Al}$ na estrutura cristalina FAU. Por outro lado, o material C3T12, com maior teor em zeólita A, apresentou menor relação $\mathrm{Si} / \mathrm{Al}$, devido à maior quantidade de $\mathrm{Al}$ na estrutura LTA.

A Figura 7 mostra as micrografias dos produtos zeolíticos C2T12 e C3T12.

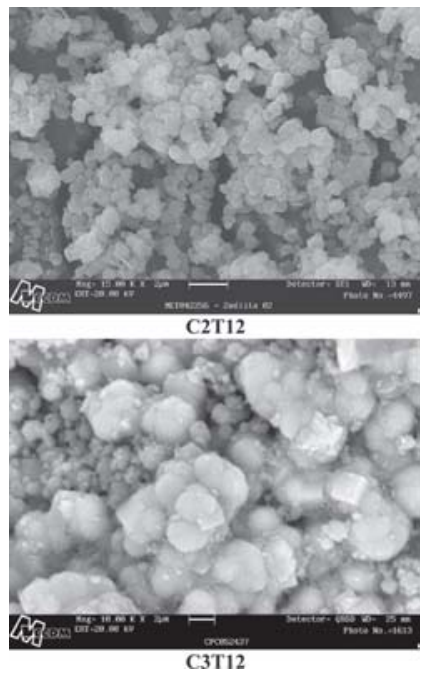

Figura 7. Micrografias dos materiais zeolíticos C2T12 e C3T12

Os materiais zeolíticos C2T12 e C3T12 apresentaram morfologias distintas. O produto obtido a partir da composição [2] apresentou partículas menores, com melhor definição dos cristais zeolíticos, verificando-se claramente o formato cúbico dos mesmos. Por outro lado, o produto sintetizado a partir da composição [3] produziu cristais maiores, mas que permaneceram agregados, provavelmente devido ao excesso de $\mathrm{NaOH}$ no meio reacional, que agiu como um ligante das partículas, ou ainda devido à presença de sílica coloidal, produzida em função do excesso de Si e da elevada alcalinidade do meio.

Para ambos os produtos, pode-se verificar que os cristais são essencialmente cúbicos, característicos das estruturas cristalinas existentes, e com estreita distribuição de tamanho de partículas, favorecida pela etapa de envelhecimento durante a síntese.

\section{Teste de troca iônica com arsênio}

Os mecanismos de adsorção podem ser descritos como o resultado da formação de complexos entre os grupos funcionais (hidroxilas) expostos na superfície mineral e as espécies químicas presentes em solução ${ }^{14}$.

O mecanismo de remoção de arsênio dá-se via troca de ligantes $^{9,15}$. Esses ligantes consistem em grupos aluminol terminais $\left(\equiv \mathrm{Al}_{\mathrm{T}}-\mathrm{OH}^{-}\right)$presentes na superfície das zeólitas, de acordo com a seguinte reação: $\equiv \mathrm{Al}_{\mathrm{T}}-\mathrm{OH}^{-}+\mathrm{H}_{2} \mathrm{AsO}_{4}^{-} \rightarrow \equiv \mathrm{Al}_{\mathrm{T}}-\mathrm{H}_{2} \mathrm{AsO}_{4}+\mathrm{OH}^{-}$. Em $\mathrm{pH}$ elevado, há uma fraca sorção de $\mathrm{H}_{2} \mathrm{AsO}_{4}{ }^{-}$devido à competição com os íons $\mathrm{OH}^{-}$da solução, enquanto em $\mathrm{pH}$ baixo, o arsenato muda de $\mathrm{H}_{2} \mathrm{AsO}_{4}-$ para $\mathrm{H}_{3} \mathrm{AsO}_{4}{ }^{0}$ devido à elevada concentração de $\mathrm{H}^{+}$na solução, reduzindo a sorção do arsênio. Por esse motivo, o $\mathrm{pH}$ das soluções foi ajustado em valores próximos a 7,5.

Os materiais zeolíticos C2T12 e C3T12, as zeólitas comerciais A e faujasita tipo-X e o xisto retortado pré-tratado foram utilizados como trocadores iônicos na remoção de arsênio de uma solução sintética contaminada. A Figura 8 mostra os resultados encontrados em bateladas de $30 \mathrm{~min}$, na temperatura de $30{ }^{\circ} \mathrm{C}$.

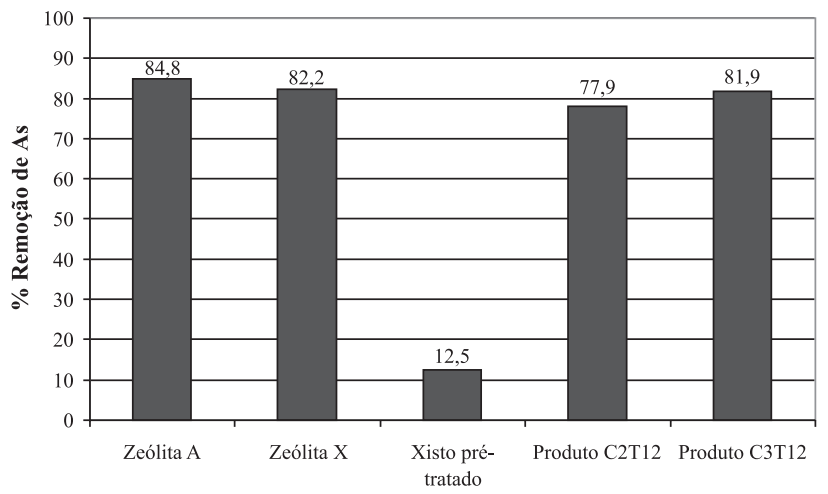

Figura 8. Remoção de arsênio (Concentração inicial: $70 \mathrm{mg} / \mathrm{L}$ ) por troca iônica em bateladas de 30 min a $30{ }^{\circ} \mathrm{C}$

Os materiais zeolíticos sintetizados apresentaram uma elevada capacidade de troca iônica, comparável às zeólitas A e faujasita tipo-X puras. Já com o xisto retortado pré-tratado, obteve-se uma remoção de As de apenas 12,5\%.

Dentre os produtos testados, o material zeolítico C3T12 mostrou-se mais eficaz no processo de troca iônica do As. Esse resultado está relacionado ao fato desse produto possuir maior teor em zeólita A. A zeólita A, por apresentar maior quantidade de Al na sua estrutura que a faujasita tipo-X, possui maior número de espécies aluminol, que conseqüentemente aumentam o número de hidroxilas superficiais trocáveis. Por outro lado, além da composição química, o diâmetro dos poros dos materiais zeolíticos também influenciou a remoção do arsênio ${ }^{6}$. A abertura de poros da zeólita faujasita $(7,8 \AA$ ) é bem maior que o diâmetro de poros da zeólita A (4,2 ̊). Desta forma, na estrutura faujasita há mais espaço para a entrada e maior velocidade de difusão dos ânions arsenato. Analisando os dois fatores, concluiu-se que, para os materiais mistos, a composição química teve maior influência no processo de troca iônica que o efeito estérico.

Comparando os resultados encontrados para as duas zeólitas comerciais, entretanto, observou-se uma diferença muito pequena, pois enquanto para a zeólita A a remoção de As foi de $84,8 \%$, a faujasita removeu $82,2 \%$. Isso indica que para os materiais puros, ambos os fatores foram igualmente importantes. 
Quanto ao desempenho, pode-se afirmar que os materiais zeolíticos mistos apresentaram uma capacidade de troca iônica muito semelhante à das zeólitas puras. Entretanto, para verificar se a cinética de troca iônica dos materiais zeolíticos sintetizados assemelha-se às zeólitas comerciais, realizou-se uma sequiência de bateladas com as zeólitas A e faujasita tipo-X comerciais e o produto de síntese C3T12. Os resultados estão mostrados na Figura 9.

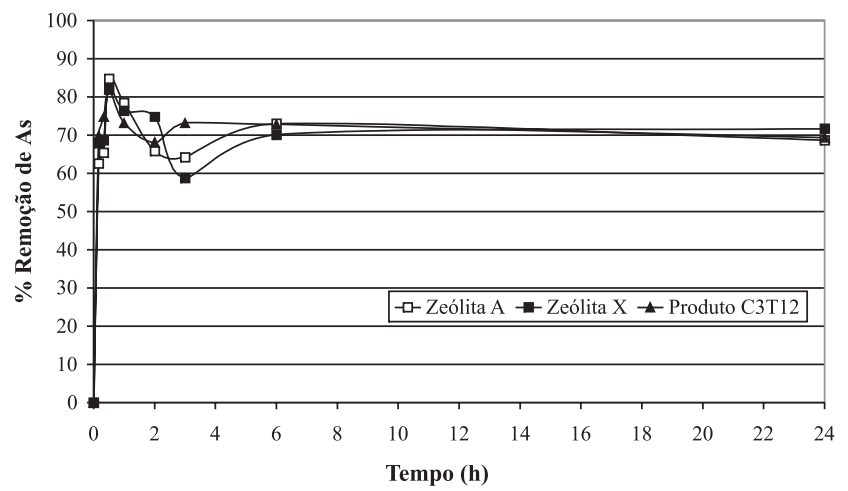

Figura 9. Cinética de troca iônica com As (concentração inicial: $70 \mathrm{mg} / \mathrm{L}$ ) nas zeólitas A e faujasita tipo-X e no produto C3T12

Analisando a Figura 9, observou-se uma intensa troca iônica em períodos curtos de reação, até $30 \mathrm{~min}$, havendo em seguida uma redução na remoção do arsênio e encontrando-se o equilíbrio de troca após $6 \mathrm{~h}$ de contato. A instabilidade verificada até a obtenção do equilíbrio pode ser atribuída à variação de $\mathrm{pH}$ do meio durante o processo de troca de ligantes ${ }^{16}$.

De acordo com as curvas obtidas, verificou-se que a mistura de fases do produto de síntese C3T12 produziu a mesma cinética de troca iônica que as zeólitas puras sendo, em determinados períodos, até mais eficiente que as zeólitas comerciais. Verificou-se, portanto, que a mistura de fases zeolíticas LTA e FAU do material sintetizado não diminuiu sua eficiência como trocador iônico, mostrando a possibilidade de aplicação desses produtos mistos em processos de separação e purificação.

Comparando-se as condições experimentais utilizadas neste trabalho a outros estudos da literatura, os resultados foram considerados favoráveis. Shevade e Ford ${ }^{9}$ utilizaram soluções de As de 50 e $100 \mathrm{mg} / \mathrm{L}$ e obtiveram uma remoção maior que $90 \%$ após $3 \mathrm{~h}$ de sorção, adicionando-se 2 g de zeólita $\mathrm{NaY}$ pura a $20 \mathrm{~mL}$ de solução. Neste trabalho, obteve-se em torno de $82 \%$ de remoção de As, partindo-se do mesmo volume $(20 \mathrm{~mL})$ de uma solução de 70 $\mathrm{mg} / \mathrm{L}$, mas a grande diferença residiu no trocador iônico empregado, um material zeolítico sintetizado a partir de xisto retortado, e na massa de material zeolítico adicionada, $100 \mathrm{mg}$. Portanto, é possível afirmar que o produto de síntese C3T12, além de obter resultados semelhantes às zeólitas puras, apresenta grande eficiência na remoção de arsênio de águas contaminadas.

\section{CONCLUSÕES}

O xisto retortado, subproduto do Processo Petrosix, após trata- mentos mecânico, térmico e ácido, apresentou características adequadas à utilização como matéria-prima para síntese de zeólitas.

O procedimento de síntese adotado favoreceu, em todas as composições utilizadas, a produção da zeólita faujasita, sendo particularmente mais efetiva com a composição [2]. Por outro lado, a formação da zeólita A foi limitada em função da quantidade insuficiente de espécies de $\mathrm{Al}$ no meio reacional. Apenas com a composição [3], mais alcalina, a dissolução das espécies de Al foi mais efetiva, favorecendo a formação da zeólita A.

Desta forma, os materiais zeolíticos com maior cristalinidade em faujasita (C2T12) e zeólita A (C3T12) foram selecionados para serem testados na remoção de arsênio em soluções contaminadas. Dentre os materiais testados, o produto $\mathrm{C} 3 \mathrm{~T} 12$, com maior teor em zeólita A, resultou em maior remoção de arsênio.

Os materiais zeolíticos sintetizados, embora possuam mistura de fases, apresentaram elevadas cristalinidade e capacidade de troca iônica com arsênio, com desempenho comparável às zeólitas A e faujasita tipo-X puras.

Finalmente, é importante ressaltar que este estudo apresentou uma possível aplicação do xisto retortado, um subproduto gerado diariamente em grande quantidade e sem aplicação, transformandoo, por meio de um procedimento de síntese de zeólitas, em um trocador iônico para purificação de águas contaminadas com arsênio.

\section{AGRADECIMENTOS}

Ao CNPq pelo apoio financeiro e ao DEQ/UFSCar pelas análises de difração de raios X.

\section{REFERÊNCIAS}

1. Santos, P. S.; Tecnologia de Argilas aplicada às Argilas Brasileiras, Ed. da Universidade de São Paulo: São Paulo, 1975.

2. Fonseca, M. C.; Cunha, T. P.; Fonseca, M. V. A.; Santos, P. S.; Cerâmica 1984, 30, 145.

3. Fernandes Machado, N. R. C.; Brumati, P. A.; Fonseca, M. V. A.; Anais do XVII Encontro sobre Escoamento em Meios Porosos, São Carlos, Brasil, 1989.

4. Gianetto, G.; Montes, A.; Rodriguez, G.; Zeolitas: Características, Propiedades y Aplicaciones Industriales, $2^{\mathrm{a}}$ ed., Ed. Innovación Tecnológica: Caracas, 2000.

5. Fernandes Machado, N. R. C.; Miotto, D. M. M.; Fuel 2005, 84, 2289.

6. Jimenes, R. S.; Dal Bosco, S. M.; Carvalho, W. A.; Quim. Nova 2004, 27, 734.

7. Fungaro, D. A.; Silva, M. G.; Quim. Nova 2002, 25, 1081

8. Pergher, S. B. C.; Caovilla, M.; Detoni, C.; Machado, N. R. C. F.; Quim. Nova 2005, 28, 397.

9. Shevade, S.; Ford, R. G.; Water Res. 2004, 38, 3197.

10. Elizalde-González, M. P.; Mattusch, J.; Einicke, W. D.; Wennrich, R.; Chem. Eng. J. 2001, 81, 187.

11. Chang, H.; Shih, W.; Ind. Eng. Chem. Res. 2000, 39, 4185.

12. Molina, A.; Poole, C.; Miner. Eng. 2004, 17, 167.

13. Somerset, V. S.; Petrik, L. F.; White, R. A.; Klink, M. J.; Key, D.; Iwuoha, E. I.; Fuel 2005, 84, 2324.

14. Basílio, M. S.; Friese, K.; Lena, J. C.; Nalini Jr., H. A.; Roeser, H. M. P.; Quim. Nova 2005, 28, 822.

15. Adamson, A. W.; Physical Chemistry of Surfaces, $5^{\text {th }}$ ed., John Wiley \& Sons: Los Angeles, 1993.

16. Miotto Bigatão, D. M. M.; Tese de Doutorado, Universidade Estadual de Maringá, Brasil, 2005. 